\title{
Effects of treatment for intestinal helminth infection on growth and cognitive performance in children: systematic review of randomised trials
}

\author{
Rumona Dickson, Shally Awasthi, Paula Williamson, Colin Demellweek, Paul Garner
}

\begin{abstract}
Objective To summarise the effects of anthelmintic drug treatment on growth and cognitive performance in children.

Data sources Electronic databases: Cochrane Infectious Diseases Group controlled trial register, Cochrane controlled trials register, Embase, and Medline. Citations of all identified trials. Contact with the World Health Organization and field researchers. Review methods Systematic review of randomised controlled trials in children aged 1-16 that compared anthelmintic treatment with placebo or no treatment. Assessment of validity and data abstraction conducted independently by two reviewers.
\end{abstract}

Main outcome measures Growth and cognitive performance.

Results Thirty randomised controlled trials in more than 15000 children were identified. Effects on mean weight were unremarkable, and heterogeneity was evident in the results. There were some positive effects on mean weight change in the trials reporting this outcome: after a single dose (any anthelmintic) the pooled estimates were $0.24 \mathrm{~kg}(95 \%$ confidence interval $0.15 \mathrm{~kg}$ to $0.32 \mathrm{~kg}$; fixed effects model assumed) and $0.38 \mathrm{~kg}(0.01 \mathrm{~kg}$ to $0.77 \mathrm{~kg}$; random effects model assumed). Results from trials of multiple doses showed mean weight change in up to one year of follow up of $0.10 \mathrm{~kg}(0.04 \mathrm{~kg}$ to $0.17 \mathrm{~kg}$; fixed effects) or $0.15 \mathrm{~kg}$ (0.00 to 0.30 ; random effects). At more than one year of follow up, mean weight change was $0.12 \mathrm{~kg}(-0.02 \mathrm{~kg}$ to $0.26 \mathrm{~kg}$; fixed effects) and 0.43 ( -0.61 to 1.47 ; random effects). Results from studies of cognitive performance were inconclusive. Conclusions There is some limited evidence that routine treatment of children in areas where helminths are common has effects on weight gain, but this is not consistent between trials. There is insufficient evidence as to whether this intervention improves cognitive performance.

\section{Introduction}

One third of the world's population is infected with one or more species of intestinal helminth, ${ }^{1}$ and public health specialists are concerned that these infections impair children's growth and development. Studies have shown associations between helminth infection and undernutrition, iron deficiency anaemia, stunted growth, poor school attendance, and poor performance in cognition tests. ${ }^{2-5}$ Better sanitation reduces transmission, but another approach is to treat children or whole populations routinely to reduce infection rates. Whether this is a sustainable solution is not clear, as rapid reinfection occurs. ${ }^{6}$ Reports of successful combined programmes spanning several decades have come from Japan.
The World Bank claims that worm infections impair learning and that helminth control is one of the most cost effective strategies to improve health in developing countries. ${ }^{8}$ Both the World Bank and World Health Organization (WHO) promote helminth control programmes in developing countries as a cost effective intervention. ${ }^{9}$ Programmes aim to "target mass treatment of children," giving all children in communities where worms are endemic anthelmintic drugs every three to six months. Treatment regimens depend on local prevalence rates. ${ }^{6-12}$ Although studies have shown that available drugs are effective in decreasing parasite infection rates, it is not clear if these approaches actually improve the growth and cognitive performance of children. ${ }^{13}{ }^{14}$ We summarised the available evidence from trials of effects of anthelmintic drug programmes on growth and cognitive performance in children.

\section{Methods \\ Inclusion criteria \\ We included all randomised and quasirandomised controlled trials in children aged 1-16 years, allocated to either anthelmintic drug treatment for intestinal nematodes with any anthelminth drug (mebendazole, piperazine, albendazole, levamisole, pyrantel, thiaben- dazole, bephenium, tetrachlorethylene, metronidazole, and ivermectin) or placebo (or no treatment). We required trials to report outcomes related to growth or cognitive performance, and these were our primary outcomes. We had no restrictions on language, publication status, or where the intervention was dispensed.}

\section{Identification of trials}

We searched the controlled trial register of the Cochrane Infectious Diseases Group, the Cochrane controlled trials register, Embase, and Medline using terms related to specific infections and specific common drugs. WHO and field researchers were contacted for unpublished or ongoing trials. Citations of all trials identified in the search were checked for further references.

\section{Study selection and data extraction}

Two reviewers independently carried out study selection and assessment of study quality (RD and PW). Data on growth outcomes were extracted independently by two reviewers using previously designed data extraction tables (RD and SA). Data related to cognitive performance were extracted by one reviewer $(\mathrm{CD})$ and checked by a second reviewer (RD). Assessment of trial quality included evaluation of concealment of allocation, method of randomisation, method of analysis, and loss to follow up.
International
Health Division,
Liverpool School of
Tropical Medicine,
Liverpool L3 5QA
Rumona Dickson
lecturer
Paul Garner
senior lecturer
Department of
Paediatrics and
Epidemiology, King
George Medical
College, Lucknow,
India
Shally Awasthi
associate professor of
paediatrics
Department of
Mathematical
Sciences, University
of Liverpool,
Liverpool L69 3BX
Paula Williamson
lecturer
Department of
Clinical Psychology,
University of
Liverpool
Colin Demellweek
lecturer
Correspondence to:
R Dickson
rdickson@livac.uk
BMJ 2000;320:1697-701

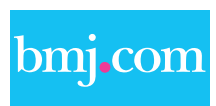

The tables of results are available on the BMJ website 


\section{Statistical analysis}

For each continuous outcome specified we calculated a pooled estimate of the weighted mean difference across the studies and applied a $\chi^{2}$ test for homogeneity. Analyses of results from single and multiple dose trials in the short term (less than one year) and long term (over one year) were undertaken separately. Within these categories analysis was carried out to compare each drug with placebo or no treatment independently and overall. When there was significant heterogeneity both fixed and random effects estimates are given. We explored heterogeneity by type of drug, age of children, and intensity of infection.

\section{Description of studies}

Thirty trials (reported in 36 reports) met the inclusion criteria (details can be found on the $B M J$ website). ${ }^{13-47}$ Of these, five (reported in seven reports ${ }^{18} 2^{30} 33^{35-37}$ ) reported cognitive outcomes, while two reports from one study included both cognitive and growth outcomes. ${ }^{45}$ Two trials that reported effects on growth or nutrition compared the effectiveness of different drug dosages or drugs and are not included in this review. ${ }^{49}$ Twenty eight trials were published reports, one was a report drafted in 1997 (S Awasthi, unpublished data), and one was an unpublished report of preliminary data from an ongoing trial. ${ }^{16}$ The results of all included trials were available in English. The trials were carried out in 17 countries in four continents (Africa, Asia, Central America, and South America). Drugs assessed in these trials included albendazole, piperazine, mebendazole, levamisole, pyrantel, and tetrachlorethylene. Follow up periods for single dose trials were from four weeks to one year (15 trials) and for multiple dose trials were from 26 weeks to six years (15 trials).

Children included in the trials were recruited from school populations in 17 trials, rural communities in nine trials, and through health clinics or health workers in four trials. Twenty seven of the included trials used "targeted mass treatment"-that is, all children were treated regardless of infection status. ${ }^{1}$ The other three trials used "targeted screening," in which children were screened and only infected children were eligible for inclusion.

Overall quality of the trials was poor. Of the 30 included studies, only three adequately reported concealed allocation, and 24 made no mention of concealment of allocation. A further three trials mentioned that the list of participants was sorted according to age, sex, or intensity of infection and then randomly allocated to treatment or control groups. Four trials specified the method of randomisation. Six trials used cluster randomisation, ${ }^{16} 2124344244$ but only two seem to have adjusted for design effects in their analysis. ${ }^{162}$

Twenty eight trials seemed to use an intention to treat analysis in so far as they reported children being analysed in the groups to which they had been randomised. One trial regrouped children after randomisation according to the number of drug treatments actually received. ${ }^{20}$ One trial excluded tall children from their analysis as the results from these children exceeded the upper limits of the comparison reference values being used. ${ }^{32}$

Analysis of different outcomes and at different times made a single estimate of loss to follow up prob- lematic. As a general rule, loss to follow up was calculated on the basis of measurements at the final testing time. In five studies the degree of loss to follow up was unclear. ${ }^{21} 222527{ }^{30}$ Eight studies had a loss to follow up of less than $10 \%$, while in 15 it was between $10 \%$ and $35 \%$. One study had loss to follow up of $40 \%,{ }^{20}$ while a second failed to collect data on more than $60 \%$ of study participants. ${ }^{44}$

Reporting of growth data varied. Some trials reported actual weight or height at the end of follow up, while others reported these variables as change in weight or height, weight for height, or weight for age. Some authors reported only a selected subset of the data and data analysis. ${ }^{21}$ Selective reporting is a concern in this review as it is unclear whether various growth outcomes were analysed but only selected findings reported.

One study acknowledged financial support for the trial from a drug company. Four stated they received the drugs used in the trial from the manufacturer.

\section{Results}

\section{Growth}

Eleven trials evaluated a single dose treatment and reported growth outcomes; two studies reported results from single and multiple drug doses (S Awasthi, unpublished data). ${ }^{16}$ An additional four multiple dose trials recorded data after their first treatment dose, and these data were included in the single dose analysis. ${ }^{19} 224045$ A subsequent sensitivity analysis that excluded data from these four multiple dose trials did not show any change in effect trends. Follow up varied from four weeks to one year.

Five single dose studies that included data on growth did not provide the data in a manner that allowed for them to be included in the meta-analysis. Four of these showed no differences in growth measures between groups, ${ }^{13} 172731$ while one showed a difference in favour of the treatment group. ${ }^{28}$ All of the tables of results are on the $B M$ /s sebsite. In summary, for single dose trials the pooled estimates of increase in weight were $0.24 \mathrm{~kg}(95 \%$ confidence interval $0.15 \mathrm{~kg}$ to $0.32 \mathrm{~kg}$; fixed effects model) and $0.38 \mathrm{~kg}(0.01 \mathrm{~kg}$ to $0.77 \mathrm{~kg}$; random effects model). For multiple dose trials the figures were $0.10 \mathrm{~kg}(0.04 \mathrm{~kg}$ to $0.17 \mathrm{~kg}$; fixed effects) and $0.15 \mathrm{~kg}$ (0.00 to 0.30 ; random effects) for up to one year of follow up and $0.12 \mathrm{~kg}(-0.02 \mathrm{~kg}$ to $0.26 \mathrm{~kg}$; fixed effects) and 0.43 ( -0.61 to 1.47 ; random effects) for more than one year of follow up.

In studies that provided data that could be used in the meta-analysis there were significant differences in relation to mean changes in weight, height, mid-upper arm circumference, triceps and subscapular skinfold measures, and mean triceps and subscapular skinfold measures.

Fourteen trials reported on the effectiveness of multiple doses with outcomes measured at one year or less. Seven trials provided data that could be used in the meta-analysis. There were significant differences in mean change in weight and in mid-upper arm circumference, and mean and mean change in triceps and subscapular skinfold measures. Seven of the 14 trials did not provide data that could be used in the meta-analysis. Of these, two trials of mebendazole found no differences in the groups. ${ }^{14}{ }^{34}$ Two studies that 
assessed levamisole reported increases in weight and height ${ }^{44}{ }^{47}$; however, the trial reported by Thein et al had a loss to follow up of over $60 \%{ }^{44}$ One trial that used pyrantel or albendazole found no differences but was confounded by a drop in rates of parasitism in control children. ${ }^{26}$ Fernando et al reported only selected data, from which no conclusions could be drawn. ${ }^{21}$ Evans et al did not carry out an intention to treat analysis because of crossovers in the trial but found that children who received treatment with pyrantel had increases in growth measures and a decrease in morbidity as measured by the development of measles. ${ }^{20}$

Results from the combination of two trials that lasted more than one year and used albendazole showed no difference between treatment and placebo groups for measures of mean weight, and the mean weight change of $120 \mathrm{~g}$ was not significant (S Awasthi, unpublished data). ${ }^{16}$

\section{Cognitive performance}

Five studies reported on the effects of treatment on measures of cognitive ability. Two studies that used albendazole attempted to assess the effects of anthelmintic treatment on academic progress. Watkins et al examined reading vocabulary and attendance records of 228 students treated with albendazole or placebo and found no difference in the groups at six months. ${ }^{46}$ Simeon et al examined performance on reading, spelling, and arithmetic tests, as well as school attendance, in 407 students and found no difference between treated and untreated children positive for trichuris. ${ }^{35}$ The loss of $35 \%$ of the school attendance records makes the interpretation of the results related to school performance difficult. This research was reported in three separate papers. Two of these studies examined the effects of anthelmintic treatment in different subgroups of children by using overlapping but differing batteries of tests of cognitive ability. ${ }^{36}{ }^{37}$ Neither study found a significant effect of treatment.

Nokes et al found some beneficial effect on some aspects of cognitive functioning. ${ }^{32}{ }^{33}$ Simeon et al failed to find this benefit, although multiple regression analysis found that children with heavy infections showed more improvement than those with lighter infections. ${ }^{35}$ Boivin and Giordani found that anthelmintic treatment with levamisole combined with iron supplementation had beneficial effects on cognitive function, but they could not separate the effects of the two treatments. ${ }^{18}$ In one other study, in which mebendazole was not effective in significantly decreasing helminth prevalence, there were no consistent changes in cognitive performance after treatment, ${ }^{30}$ but the authors attributed the lack of effect to the failure of drug treatment. They consequently attempted to replicate their study by using treatment specific for helminth infection. Unfortunately a natural disaster (flood) precluded data collection in the second study. Hadidjaja et al compared the use of mebendazole alone or in combination with health education. ${ }^{24}$ Their groups, however, were not comparable at inception, and loss to follow up was over $30 \%$, with losses in some groups over $50 \%$. All studies that examined effects of treatment on cognitive performance also measured growth factors such as height and weight. Only one study, however, provided data in a form that could be used in the meta-analysis. ${ }^{45} 46$

\section{Discussion}

The main question examined in this review was the effect of anthelmintics on growth and cognitive performance. Therefore we did not examine drug effects on intermediate outcomes such as worm infection. Head to head comparisons of different drugs are not included as these are not relevant until benefits in placebo controlled comparisons have been shown. We did not consider intermediate laboratory variables such as haemoglobin concentration. In fact, of the trials that met our inclusion criteria only three reported this outcome in a manner that could be used in the meta-analysis, and the evidence of an effect is limited..$^{50}$

We intended to analyse effects by prespecified factors that could influence these estimates, including the presence of malnutrition, infection species, and intensity of infection. We also intended to stratify our analysis by age, as this will strongly influence the size of many growth outcomes. The data available from individual trials, however, were insufficient to allow subgroup analysis or meta-regression by any of these factors. Analysis of data from individual patients might start to unravel these subgroup effects but would be a large task.

Not unexpectedly, and probably related to the factors mentioned above, several meta-analyses showed heterogeneity between the results from different trials. We considered presenting only those results with no heterogeneity. Most growth outcomes are correlated within patients, however, so we judged that reporting only those meta-analyses where heterogeneity was absent would be a bias in itself. For this reason, we present all meta-analyses, and, where there was significant heterogeneity, we have provided analysis using both fixed and random effects models. The wide confidence intervals with random effects reflect the heterogeneity in the available data. Full details of individual trial data are available from the Cochrane Library. ${ }^{50}$

\section{The trials}

The analysis highlighted several methodological issues that should be examined in future trials. Firstly, trial quality varied. Most trials were small, and few reported that they concealed allocation.

Secondly, most researchers obtained multiple growth measures, but their reporting of these was inconsistent. Authors variously reported absolute values, changes in values, indices of values (such as weight for height, height for age), and comparison of values with accepted international reference data Researchers did not indicate their a priori primary outcome. We were therefore unable to assess whether the data presented were the intended primary outcomes or whether a number of growth outcomes were measured with the authors reporting only on significant results. This bias, termed selective reporting, may be done unwittingly by researchers but is potentially an important unresearched source of bias in systematic reviews of published literature.

Thirdly, growth is an indirect measure of health outcome, and only one study examined more direct 
measures such as illness or mortality. Evans et al attempted to examine morbidity measures such as episodes of diarrhoea, respiratory infection, or measles. ${ }^{20}$ The results of their study indicated that there were fewer episodes of measles in treated children.

Finally, policy makers assume that these interventions improve school attendance, and we specifically sought this outcome. Two studies measured this, and neither found an effect. Other studies used cognitive tests, but what these mean and how they relate to a child's wellbeing is not clear. Researchers used a wide range of tests, which made direct comparison difficult. Even when the same test was used, such as the digit span (forwards) and verbal fluency test, the effects were not consistent between studies. Again, the hypothesis that routine anthelmintic treatment will benefit a subgroup of the population could not be explored with the data available to us. A further difficulty is that most tests for cognitive performance have not been validated outside Western countries. ${ }^{51}{ }^{52}$

On the other hand, the real problems in implementing these trials should not be underestimated, and difficulties can result in contamination, which mitigates against the detection of true effect differences between groups. In the study by Evans et al, in which fortnightly assessments were carried out, the researchers found that a proportion $(>30 \%)$ of children in the placebo group had actually received intermittent anthelmintic treatment. ${ }^{20}$ The reported crossover rate in the Awasthi trial further indicates the difficulty in maintaining treatment groups within a study population (S Awasthi, unpublished data).

\section{Policy implications}

Our interpretation of these findings is that the evidence of benefit for mass treatment of children related to positive effects on growth and cognitive performance is not convincing. In the light of these data, we would be unwilling to recommend that countries or regions invest in programmes that routinely treat children with anthelmintic drugs to improve their growth or cognitive performance.

\section{Research implications}

There is a need for good quality, properly concealed, placebo controlled trials to investigate the impact on these outcomes. It is inefficient, unjustified, and irrelevant to carry out head to head comparisons of different anthelmintic drugs. A large cluster, randomised trial in India is currently examining mortality as an outcome, and the results of this work will be an important contribution. International coordination, possibly through the $\mathrm{WHO}$, is required to ensure that future trials are similar in design and that researchers agree in advance to pool individual patients' data in a meta-analysis and to explore hypotheses about subgroup effects in relation to age, worm load, and exposure to infection.

We thank the advisory panel for this review (Dr M Albonico, Dr G Barnish, Dr D Bundy, and Dr L Savioli) and Dr P Donnen for his prompt responses to our requests for data. A more detailed version of this review is published on the Cochrane Library and will be maintained as new evidence emerges.

Contributors: RD wrote the protocol, assisted all aspects of the review process, organised specialist advice and input, drafted the review, and organised its final production. SA assisted in
What is already known on this topic

Many children in developing countries are infected by intestinal helminths and infection is associated with poor nutrition

In endemic areas the World Bank and others widely promote routine regular mass treatment of children with anthelmintics

\section{What this study adds}

There is little evidence to support the use of routine anthelmintic treatment to improve growth and cognitive performance in children in developing countries

assessment of study inclusion and data extraction. PW assisted in assessment of study quality and data analysis. CD extracted cognitive data and interpreted the results. PG conceived the idea, guided the protocol development, contributed to the data interpretation, and provided support in the preparation of both the Cochrane review and this manuscript. All authors commented on drafts of this publication. PG is guarantor.

Funding: Department for International Development UK and the European Union Directorate General XII. The panel and the funding agencies have no responsibility for the data presented and the views expressed.

Competing interests: SA is currently supported by Unicef and the World Bank to carry out a trial of anthelmintic drugs in children. No author is currently receiving support from drug companies manufacturing anthelmintics.

1 Warren K, Bundy D, Anderson R, Davis A, Henderson D, Jamison, et al. Helminth infection. In:Jamison D, Mosley W, Measham A, Bibadilla J, eds. Disease control priorities in developing countries. Oxford: Oxford Publishing, 1993.

2 Simeon D, Callender J, Wong M, Grantham-McGregor S, Ramdath DD. School performance, nutritional status and trichuriasis in Jamaican schoolchildren. Acta Paediatr 1994;83:1188-93.

3 Savioli L, Bundy DAP, Tomkins A. Intestinal parasitic infections a soluble public health problem. Trans R Soc Trop Med Hyg 1992;86:353-4.

4 Nokes C, Bundy D. Does helminth infection affect mental processing and educational achievement? Parasitol Today 1994;10:14-8.

5 Evans DB, Guyatt HL. The cost-effectiveness of mass drug therapy for intestinal helminths. Pharmacoeconomics 1995:8:14-22.

6 World Health Organization. Report of the WHO informal consultation on the use of chemotherapy for the control of morbidity due to soil-transmitted nematodes in humans. Geneva: WHO, 1996.

7 Yokogawa M, Kojima S, Araki K, Ogawa K, Niimura M, Kagei N, et al. Mass treatment for enterobiasis vermicularis with pyrantel pamoate. Jpn J Parasitol 1970;19:593.

8 World Bank. World development report 1993:investing in health. Washington: World Bank, 1993.

9 World Health Organization. Guidelines for the evaluation of soil-transmitted helminthiasis and schistosomiasis at community level: a guide for managers of control programmes. Geneva: WHO, 1998.

10 Hall A, Orinda V, Bundy D, Broun D. Promoting child health through helminth control-a way forward? Parasitol Today 1997;13:411-3.

11 World Health Organization. Informal consultation on intestinal helminth infections. Geneva: WHO, 1990.

12 World Health Organization. Strengthening interventions to reduce helminth infections. Geneva: WHO, 1997. (WHO/SCHOOL/96.1 ed.)

13 Greenberg BL, Gilman RH, Shapiro H, Gilman JB, Mondal G, Maksud M, et al. Single dose piperazine therapy for Ascaris lumbricoides: an unsuccessful method of promoting growth. Am J Clin Nutr 1981;34:2508-16.

14 Lai K, Kaur H, Mathias R, Ow-Yang C. Ascaris and trichuris do not contribute to growth retardation in primary school children. SEA J Trop Med Pub Health 1995;26:322-8.

15 Adams EJ, Stephenson LS, Latham MC, Kinoti SN. Physical activity and growth of Kenyan school children with hookworm, Trichuris trichiura and Ascaris lumbricoides infections are improved after treatment with albendazole. J Nutr 1994;124:1199-206.

16 Awasthi S, Peto R, Fletcher R, Glick H. Controlling parasitic infection in children under five years of age: giving albendazole in conjunction with an Indian government vitamin A supplement program. Philadelphia: International government vitamin A supplement pro.

17 Beach MJ, Streit TG, Addiss DG, Prospere R, Lafontant JG, Lammie PJ. Assessment of combined invermectin and albendazole for treatment of intestinal helminth and Wuchereria bancrofti infections in Haitian school children. Am J Trop Med Hyg 1999;60:479-86.

18 Boivin MJ, Giordani B. Improvements in cognitive performance for schoolchildren in Zaire, Africa, following an iron supplement and treatment for intestinal parasites. J Pediatr Psychol 1993;18:249-64. 
19 Donnen P, Brasseur D, Dramaix M, Vertongen F, Zihindula M, Muhamiriza M, et al. Vitamin A supplementation but not deworming improves growth of malnourished preschool children in eastern Zaire. J Nutr 1998;128:1320-7.

20 Evans J, Martin J, Mascie-Taylor C. The effect of periodic deworming with pyrantel pamoate on the growth of pre-school children in northern Bangladesh. London: Save the Children Fund, 1986.

21 Fernando MA, Balasuriya, Somaratne. Effect of Ascaris lumbricoides infestation on growth of children. Indian Pediatr 1983;20:721-31.

22 Freij L, Meeuwisse G, Berg NO, Walland S, Gerbre-Medhin M. Ascariasis and malnutrition: a study in urban Ethiopian children. Am J Clin Nutr $1979 ; 32: 1545-53$

23 Gupta M, Urrutia J. Effect of periodic antascaris and antigiardia treatment on nutritional status of preschool children. Am J Clin Nutr 1982;36:79-86.

24 Hadidjaja P, Bonang E, Suyardii A, Abidin A, Ismid I, Margono S. The effect of intervention methods on nutritional status and cognitive function of primay school children infected with Ascaris lumbricoides. Am J Trop Med Hyg 1998;59:791-5

25 Hadju V, Stephenson LS, Abadi K, Mohammed HO, Bowman DD, Parke RS. Improvements in appetite and growth in helminth-infected schoolboys three and seven weeks after a single dose of pyrantel pamoate. Parasitology 1996:113:497-504.

26 Hadju V, Satriono, Abadi K, Stephenson L. Relationship between soil-transmitted helminthiases and growth in urban slum school children in Ujung Pandang, Indonesia. Int J Food Sci Nutr 1997;48:85-93.

27 Kloetzel K, Merluzzi FT, Kloetzel D. Ascaris and malnutrition in a group of Brazilian children - a follow up study.J Trop Pediatr 1982;28:41-3

28 Koroma MM, Williams RAM, De La Have R, Hodges M. Effects of albendazole on growth of primary school children and the prevalence and intensity of soil-transmitted helminths in Sierra Leone. I Trop Pediat $1996 ; 42: 371-2$.

29 Kruger M, Badenhorst CJ, Mansvelt EPG, Laubscher JA, Benade AJS. The effect of iron fortification in a school feeding scheme and anthelmintic therapy on the iron status and growth of 6-8 year old school children. Food Nutr Bull 1996;17:11-21.

30 Kvalsvig JD, Cooppan RM, Connolly KJ. The effects of parasite infections on cognitive processes in children. Ann Trop Med Parasitol 1991;85:551 68.

31 Michaelsen KF. Hookworm infection in Kweneng District, Botswana. A prevalence survey and a controlled treatment trial. Trans $R$ Soc Trop Me Hyg 1985;79:848-51.

32 Nokes C, Grantham-McGregor SM, Sawyer AW, Cooper ES, Bundy DA Parasitic helminth infection and cognitive function in school children. Proc R Soc Lond Biol Sci 1992;247:77-81.

33 Nokes C, Grantham-McGregor SM, Sawyer AW, Cooper ES, Robinson BA, Bundy DA. Moderate to heavy infections of Trichuris trichiura affect cognitive function in Jamaican school children. Parasitology 1992;104:539-47.

34 Rousham E, Mascie-Taylor CG. An 18-month study of the effect of periodic anthelmintic treatment on the growth and nutritional status of preschool children in Bangladesh. Ann Hum Bio 1994;21:315-24.

35 Simeon DT, Grantham-McGregor SM, Callender JE, Wong MS. Treatment of Trichuris trichiura infections improves growth, spelling (1950 $125: 1875-83$.

36 Simeon DT, Grantham-McGregor SM, Wong MS. Trichuris trichiur infection and cognition in children: results of a randomized clinical trial. Parasitology 1995;110:457-64.
37 Meeks Gardner JM, Grantham-McGregor S, Baddeley A. Trichuris trichiura infection and cognitive function in Jamaican school children Ann Trop Med Parasitol 1996;90:55-63.

38 Stephenson LS, Latham MC, Kurz KM, Kinoti SN, Brigham H. Treatment with a single dose of albendazole improves growth of Kenvan schoolchildren with hookworm, Trichuris trichiura, and Ascaris lumbricoides infections. Am J Trop Med Hyg 1989;41:78-87.

39 Stephenson LS, Latham MC, Kinoti SN, Kurz KM, Brigham H. Improvements in physical fitness of Kenyan school boys infected with hookworm, Trichuris trichiura, and Ascaris lumbricoides following a single dose of albendazole. Trans R Soc Trop Med Hyg 1990;84:277-82.

40 Stephenson LS, Latham MC, Adams EJ, Kioti SN, Perter A. Weight gain of Kenyan school children infected with hookworm, Trichuris trichiura and Ascaris lumbricoides is improved following once- or twice-yearly treatment with albendazole. J Nutr 1993;123:656-65.

41 Stephenson LS, Latham MC, Adams EJ, Kinoti SN, Pertiet A. Physical fitness, growth and appetite of Kenyan school boys with hookworm, Trichuris trichiura and Ascaris lumbricoides infections are improved four months after a single dose of albendazole. J Nutr 1993;123:1036-46.

42 Stoltzfus R, Albonico M, Chwaya H, Tielsch J, Schulze K, Savioli L. Impact of the Zanzibar school-based deworming program on iron status of children. Am J Clin Nutr 1998;68:179-86.

43 Stoltzfus RJ, Albonico M, Tielsch J, Chwaya H, Savioli L. School-based deworming program yields small improvement in growth of Zanzibar school children after one year. J Nutr 1997;127:2187-93.

44 Thein H, Thane T, Than S, Myat LK, Myint L. A controlled chemotherapeutic intervention trial on the relationship between Ascaris lumbricoides infection and malnutrition in children. Trans $R$ Soc Trop Med Hyg 1991;85:523-8.

45 Watkins WE, Pollitt E. Effect of removing Ascaris on the growth of Guatemalan schoolchildren. Pediatr 1996;97:871-6.

46 Watkins W, Cruz JR, Pollitt E. The effects of deworming on indicators of school performance in Guatemala. Trans $R$ Soc Trop Med Hyg 1996;90:156-61.

47 Willett WC, Kilama WL, Kihamia CM. Ascaris and growth rates: a randomized trial of treatment. Am J Public Health 1979;69:987-91.

48 Forrester J, Bailar J, Esrey S, Jose M, Castillejos B, Ocampo G. Randomised trial of albendazole and pyrantel in symptomless trichuriasis in children. Lancet 1998;352:1103-8.

49 Beasley N, Tomkins A, Hall A, Kihamia C, Lorri W, Nduma B, et al. The impact of population level deworming on the haemoglobin levels of school children in Tang, Tanzania. Trop Med Int Health 1999;4:744-50.

50 Dickson R, Awasthi S, Demellweek C, Williamson P. Anthelmintic therapy in children-effects on growth and cognitive performance. In: Cochrane Collaboration. Cochrane Library. Issue 2. Oxford: Update Software, 2000.

51 Baddeley A, Meeks Gardner J, Grantham-McGregor S. Cross-cultural cognition: developing tests for developing countries. Appl Cogn Psychol 1995;9:S173-95

52 Grantham-McGregor S. Assessments of the effects of nutrition on mental development and behavior in Jamaican studies. Am J Clin Nutr 1993:57:303-9S.

(Accepted 16 March 2000)

\section{A book that changed my practice New insights into mental illness}

It had all become depressingly familiar: the suicidal teenager with relationship difficulties; a middle-aged office worker who had lost the energy to keep going; a lonely pensioner with insomnia and multiple functional complaints. The answer to all of these and many more was: start an antidepressant, take a few moments to hear their complaints, refer for some counselling. And yet many times nothing really helped. Despite the much vaunted hype and advertising of antidepressants, most GPs will know how little they can do for the patients we see daily. ${ }^{1}$

But then a friend gave me The Awakening by F Zuendel. ${ }^{2}$ At first glance, it seemed irrelevant: an account of a 19th century German pastor by the name of Blumhardt, working in the Black Forest. But I read on to find a surprising record of people with mental and physical illness, on whom the medical establishment had given up. They found complete remission of their disease-all carefully documented. How could this be explained?

Blumhardt knew that most psychiatrists of his day-like today-ignore the fact that people have an innate sense of right and wrong, and that no amount of drugs or counselling could relieve them from the sense of burden they felt over past wrong doings. Medical treatment was unable to offer them what they needed most: forgiveness. This was not a question of dramatic emotional conversions, but simply a chance to share with a confidante and feel forgiven.
Though this flies in the face of scientific theory, even the most cynical will have to admit that we do not understand all there is to know about mental illness, and the fact that the mind may be influenced in ways other than through pharmacologically defined pathways should come as no surprise. Blumhardt had a great respect for the medical profession and believed that it was the church which was failing: "Especially in the case of mental illness, most pastors cut a pathetic figure alongside physicians." He set out to change this, with surprising results.

So how has my practice changed? After reading this book, several of my patients have been able to speak openly to fellow church members in a way that they had not done for many years. The result has been that they have come off their antidepressants and are leading happier and more fulfilled lives. I have not seen miracle cures or anything spectacular; I haven't just blindly stopped all antidepressants. But this new line of approach in what seemed to be a dead end street has been most welcome. This book opened up new dimensions to me and brought help to patients who previously seemed beyond help.

\section{EJ Ben-Eliezer GP locum, East Sussex}

1 Venning G. Antidepressant drugs have been shown to be ineffective in mild depression. BMJ 2000;320:311.

2 Zuendel F. The Awakening. Robertsbridge, UK: Plough Publishing House,1999. 